\title{
FRICTION PROPERTIES AND DISTRIBUTION RULE OF LUBRICANT FILM OF FULL CERAMIC BALL BEARING UNDER DIFFERENT SERVICE CONDITION
}

\author{
JIAN SUN*, **, YUHOU WU**, JIAXING YANG**, ${ }^{*}$ JINMEI YAO**, ZHONGXIAN XIA** \\ *School of Mechanical Engineering, Tsinghua University, Beijing 100084, China \\ **School of Mechanical Engineering, Shenyang Jianzhu University, Shenyang 110168, China \\ \#E-mail: ynslsa69@163.com
}

Submitted November 17, 2021; accepted December 16, 2021

\begin{abstract}
Keywords: Full ceramic ball bearing, Friction properties, Lubricant film, Distribution rule, Mathematical model
Full ceramic ball bearings are widely used in extreme and complex conditions, such as ultra-high/low temperature, ultrahigh speed, corrosion and insulation, because of their material specificity. In order to reveal the friction and lubrication properties, improve the service performance life of all ceramic ball bearings, a mathematical model of the oil lubrication for full ceramic ball bearings has been established in this paper. The distribution rule of the lubricant film in the contact area under different speeds and loads were analysed. The main factors influencing the peak mutation of the lubricant film pressure are clearly defined. The results are compared and analysed by using a ball-disc rolling lubricant film test machine. The study found that the thickness of the lubricant film of a full ceramic ball bearing is positively correlated with the bearing speed and negatively correlated with the bearing loads. The bearing speed has a relatively large effect on the change in the lubricant film thickness. The pressure of the lubricant film in the contact area is positively correlated with the bearing speed, but it is not affected by the bearing load. Unlike metal ball bearings, the thickness and pressure of the lubricant film have a greater relative rate of change in different positions in the contact area of full ceramic ball bearings. With an increase in the bearing speed, the necking-down effect has a greater influence on the peak mutation of the oil pressure. Only one pressure peak occurs in the oil film in the contact area. The results of this paper play an important role in revealing the friction and lubrication properties of full ceramic ball bearings and improving their service performance and life under oil lubrication conditions.
\end{abstract}

\section{INTRODUCTION}

Full ceramic ball bearings refer to high-tech bearing products whose rings and rolling bodies are made of ceramic materials. They can be widely used in aerospace, navigation, metallurgy, the chemical industry, national defence and military fields [1-3]. Because full ceramic ball bearings work at high speed, frequently start-stop, have variable loads, overload, are subject to vibrations and go through other harsh working conditions, they often operate in a state of mixing and boundary lubrication [4$8]$, which causes pitting wear on the rolling body and raceway surface of the ring, and then leads to the failure of the full ceramic ball bearings. According to statistics, the failure of full ceramic ball bearings caused by poor lubrication accounts for about $72.2 \%$ [9-10].

In recent years, some experts and scholars have begun to study the lubrication mechanism of full ceramic ball bearings and its influence on the bearing damage, operation performance, service life and other aspects. Zhou et al. [11-12] compared the operating conditions of full ceramic ball bearings and steel ball bearings without lubrication by fatigue life tests, where the temperature rise, vibration and fatigue life of both were recorded. Wen et al. [13] studied the friction and wear mechanism of silicon nitride hybrid ceramic ball bearings and found that the hybrid ceramic ball bearings had adhesion wear, fatigue wear and abrasive wear under dry friction conditions. Yuan et al. [14] studied the temperature rise and vibration characteristics of hybrid ceramic ball bearings under different lubricant viscosity conditions. The relationship between lubricant viscosity, lubrication status and bearing performance was clarified. Su et al. [15] studied the grease lubrication technology of hybrid ceramic ball bearings and established a grease lubrication supply model applicable to hybrid ceramic ball bearings. Yan et al. [16] analysed the influence of water lubrication on the operation performance of ceramic ball bearings and a spindle system, and established a high-speed ceramic ball bearing water-lubricated model that takes many factors into account, such as the bearing structure, highspeed turbulence, thermal effect and elastic deformation. Based on the elastohydrodynamic lubrication geometric model of water-lubricated hybrid ceramic ball bearings, Zhang et al. [17] studied the influence of the water supply pressure on the pressure lubricant film thickness of waterlubricated hybrid ceramic ball bearings under different working conditions. Huang and Liu [18] established a thermal elastohydrodynamic lubrication mathematical model applicable to ceramic ball bearings, and found 
through comparative tests that, under the same working parameters, the lubricant film pressure of ceramic ball bearings was lower than that of steel bearings, and the lubricant film thickness was higher than that of steel bearings. Han et al. [19] analysed the formation process of a lubricant film on the surface of a bearing raceway during operation based on the comprehensive effect of fluid dynamics and boundary lubrication. Galiev et al. [20] proposed a distribution analysis model of a lubricant film considering the Erying characteristic stress, ultimate shear stress and shear elastic modulus under high shear rate elastohydrodynamic lubrication. Antonio-García et al. [21] studied the influence of a lubricant film thickness on the bearing service performance under hydrodynamic lubrication conditions. Cho [22] improved the Elrod algorithm based on the mass conservation boundary conditions, and obtained the governing equation and the lubrication equation of the complete oil film region that can automatically determine the dynamic boundary. Biswas et al. [23] studied the lubrication performance of medium-low speed bearings under different load conditions, changes in the oil film thickness, oil film pressure and oil film velocity. Dmitrichenko et al. [24] established a dynamic model of ball bearings and studied the influence of different distribution models of lubricants and the fluid dynamic pressure on the dynamic characteristics of bearings. At present, there are few research studies on the lubrication mechanism of full ceramic ball bearings. Most of the research results are mainly used to solve the poor lubrication of hybrid ceramic ball bearings and the problems caused by it.

In this paper, a mathematical model of a lubricant film suitable for full ceramic ball bearings is established. The influence of the slip ratio on the friction performance of rolling bearings at different rotational speeds is investigated by numerical analysis methods. A series of curves of friction coefficients with a slip ratio and lubricant film thickness are obtained. At the same time, the lubricant film thickness and pressure distribution are observed and analysed by a ball-disc contact optical interference lubricant film measuring device, and then the lubricant film state and distribution rules are clearly defined. On this basis, a comparative study is carried out with the theoretical analysis results. The research results are of great significance for improving the lubrication theory of full ceramic ball bearings.

\section{MATHEMATICAL MODEL OF THE FULL CERAMIC BALL BEARING}

Equations of equilibrium

Taking a 6206CE full ceramic ball bearing as the research object, the contact between the ball and the inner and outer ring of the ball bearing can be regarded as point-to-face contact. In addition, the lubrication problem of the ball/outer ring tribology system can be regarded as a plane contact elastohydrodynamic lubrication problem when the ball bearing contact with the micro area is taken as the research object [25-26]. The oil lubricating system of the $6206 \mathrm{CE}$ full ceramic ball bearing and its friction pair between the roller and outer ring are shown in Figure 1.

In Figure 1b, $n$ is the inner ring speed. $n_{r}$ is the rotation speed of the ball. $R_{e}$ is the radius of curvature of the outer raceway. $R_{r}$ is the radius of curvature of the ball. $R_{e r}$ is the equivalent radius of the curvature. $u_{1}, u_{2}$ are the velocities of the upper and lower surfaces of the friction pair, respectively. The lubricant film gap between the ball and the outer ring is:

$$
\left\{\begin{array}{l}
h(x)=h_{0}+\frac{x^{2}}{2 R_{e r}}+v(x) \\
R_{e r}=\frac{R_{e} R_{r}}{R_{e}+R_{r}}
\end{array}\right.
$$

where $h_{0}$ is the minimum oil film thickness, $v(x)$ is the elastic displacement of each point in the vertical direction [27].

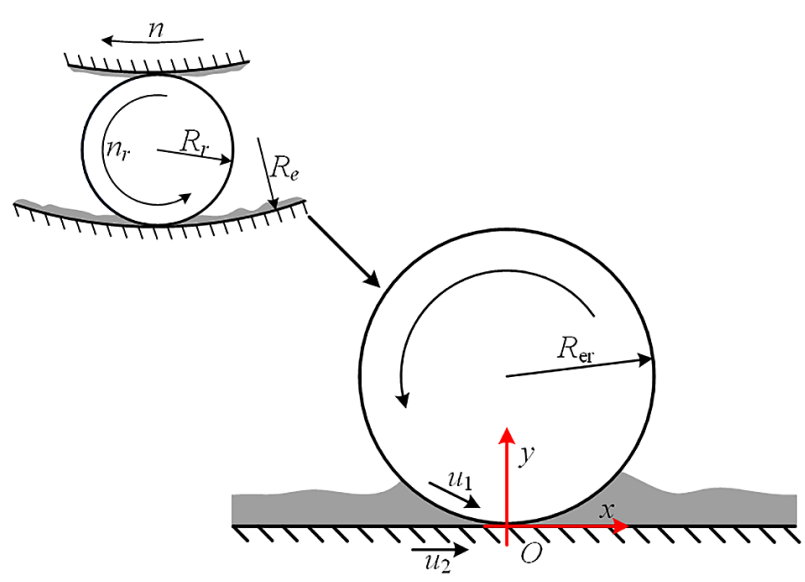

b) The friction pair between the roller and outer ring

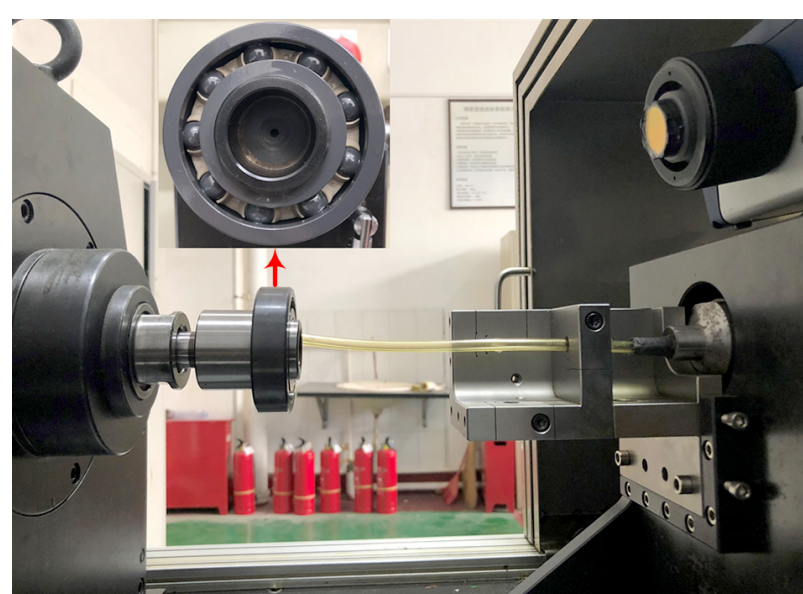

a) Lubrication system of the $6206 \mathrm{CE}$ ball bearing

Figure 1. Friction and lubrication of the 6206CE full ceramic ball bearing. 
Pure rolling is performed between the ball and the raceway. The rotation speed of the ball is:

$$
n_{r}=\frac{\left(1+2 s_{q}\right) n}{2 s_{g}\left(1+s_{g}\right)}
$$

The revolution speed of the ball is:

$$
\left\{\begin{array}{l}
n_{g}=\frac{n}{2\left(1+s_{g}\right)} \\
s_{g}=\frac{R_{r}}{R_{e}}
\end{array}\right.
$$

According to the hydrodynamic lubrication theory, the relationship between the lubricant film thickness and the lubricant film pressure can be determined by solving Reynold's equation. In the plane friction pair, the lubricant film between two relative moving surfaces in an ideal smooth state cannot produce a hydrodynamic bearing capacity. In order to produce the hydrodynamic bearing capacity of the lubricant film between the surfaces of the friction pair, in addition to the relative motion velocity of the two planes, it is also required to have a certain convergent gap along the direction of motion. There is a convergence-divergence gap in the ball/outer ring friction pair. Therefore, the following equation should be used to calculate the lubricant film distribution:

$$
\begin{gathered}
\frac{\partial}{\partial x}\left(\frac{\rho}{\mu} h^{3} \frac{\partial p}{\partial x}\right)=12 u_{e} \frac{\partial[(1-\theta) \rho h]}{\partial x} \\
p+\theta-\sqrt{p^{2}+\theta^{2}}=0 \\
u_{e}=\frac{u_{1}+u_{2}}{2}
\end{gathered}
$$

where $h$ is the lubricant film thickness, $p$ is the fluid pressure, $\theta$ is the cavity factor, which is the parameter related to the cavity and affected by the fluid pressure when taking $\theta=0 . u_{e}$ is the entrainment velocity. The relationship for the ball/outer ring tribology system is as follows:

$$
\left\{\begin{array}{l}
u_{1}=\frac{2 \pi R_{e}}{60 n_{r}} \\
u_{2}=C
\end{array}\right.
$$

When the fluid pressure is greater than the cavity pressure $(p>0)$ and taking $\theta=0$. When a cavity occurs, the fluid pressure is equal to the cavity pressure $(p=0)$ taking $\theta>0$, and its value is within $0-1$.

\section{Properties of the lubricating oil}

The viscosity of the lubricating oil has an important effect on the lubricant film pressure and friction power consumption of the friction system of ball bearings, and it changes with a change in the temperature and shear rate. Ball bearings often work under complex working conditions, such as ultra-high speed and heavy load. The shear thinning effect of the lubricant film caused by the friction temperature rise and high variable stress field will lead to the shear failure of the long chain molecules of oil additives, and the viscosity of the lubricating oil will decrease with an increase in the shear rate. Therefore, it is necessary to consider the influence of the lubricant film temperature and shear rate on the viscosity of the lubricating oil in the analysis of the lubrication system.

\section{Viscosity-pressure and viscosity-temperature effect}

The most important factors affecting the viscosity of the lubricating oil are the pressure and temperature of the lubricating oil. The relationship between the lubricating oil viscosity and the lubricating oil temperature and pressure is:

$$
\left\{\begin{array}{l}
\mu=\mu_{0} \exp \left\{\left(\ln \mu_{0}+9.67\right)\left[\left(1+5.1 \times 10^{-9} p\right)^{a}\right]-1\right\} \\
\mu_{0}=a_{0} \exp \left(\frac{T_{1}}{T_{2}+T}\right)
\end{array}\right.
$$

where $T$ is the temperature of the lubricating oil, $a_{0}, T_{1}$ and $T_{2}$ are all the correction parameters [28], $a$ is related to the lubricating oil properties and is usually 0.68 . The formula combines the viscosity-temperature formula of Vogel and the viscosity-pressure formula of Roelands.

\section{Shear thinning effect}

The lubricating oil viscosity is affected by the shear thinning effect. The relationship between the shear rate and the lubricating oil viscosity can be expressed by the Cross formula:

$$
\left\{\begin{array}{l}
\mu=\mu_{h}+\frac{\left(\mu_{1}-\mu_{h}\right)}{1+n_{1} \dot{\gamma}^{n 2}} \\
\dot{\gamma}=\frac{|U|}{h}
\end{array}\right.
$$

where $\mu_{1}$ and $\mu_{h}$ are the viscosity of the lubricating oil at low and high shear rates, $n_{1}$ and $n_{2}$ are the fitting parameters related to the lubricating oil, $\dot{\gamma}$ is the shear rate.

\section{Density-pressure and density-temperature effect}

The density of the lubricating oil varies with the pressure and temperature of the lubricating oil. According to Equation 10, the relationship between the density, pressure and temperature of the lubricating oil can be obtained as follows:

$$
\rho=\rho_{0}\left(1+\frac{0.6 \rho}{1+1.7 p}\right)\left[1-\beta_{T}\left(T-T_{0}\right)\right]
$$

where $\rho_{0}$ is the lubricating oil density at temperature $T_{0}$ under atmospheric pressure. $P$ is the density of the oil at $20{ }^{\circ} \mathrm{C}$ under atmospheric pressure, known as the standard density. $\beta_{T}$ is the temperature expansion coefficient of the lubricating oil [29]. Mobil 5W30 was used as the lubricating oil, and its parameters are shown in Table 1. 
Table 1. 5W30 lubricant parameters.

\begin{tabular}{lc}
\hline Parameters & Value \\
\hline$\rho_{0}\left(\mathrm{~kg} \cdot \mathrm{m}^{-3}\right)$ & 860 \\
$\beta_{T}\left(\mathrm{~K}^{-1}\right)$ & $6.4 \times 10^{-4}$ \\
$\mu_{\mathrm{h}} / \mu_{1}$ & 0.71 \\
$a_{0}\left(\mathrm{MPa} \cdot \mathrm{s}^{-1}\right)$ & 0.158 \\
$T_{1}\left({ }^{\circ} \mathrm{C}\right)$ & 700 \\
$T_{2}\left({ }^{\circ} \mathrm{C}\right)$ & 70 \\
\hline
\end{tabular}

Elastic deformation

Surface elastic deformation needs to be considered in the simulation analysis. According to the elastic theory, the elastic displacement of each point along the vertical direction can be deduced as follows:

$$
\left\{\begin{array}{l}
v(x)=-\frac{2}{\pi E} \int_{s_{1}}^{s_{2}} p(s) \ln (s-x)^{2} d s+c \\
\frac{1}{E}=\frac{1}{2}\left(\frac{1-v_{e}{ }^{2}}{E_{e}}+\frac{1-v_{r}{ }^{2}}{E_{r}}\right)
\end{array}\right.
$$

where $p(s)$ is the load distribution function [30], and for the elastohydrodynamic lubrication, $p(s)$ is the fluid pressure distribution, $s$ is an additional coordinate on the $x$-axis, indicating the distance between $p(s)$ and the origin of the coordinate, $s_{1}$ and $s_{2}$ are the starting point and ending point coordinates of the load, respectively. $c$ is an undetermined constant, which can usually be incorporated into $h_{0} . E$ is the valid elastic modulus, $E_{e}$ is the elastic modulus of the outer raceway, $E_{r}$ is the elastic modulus of the ball, $v_{e}$ is Poisson's ratio of the outer raceway, $v_{r}$ is Poisson's ratio of the ball.

\section{SIMULATION ANALYSIS}

\section{Calculation process}

The simulation flow chart of the numerical calculation is shown in Figure 2.

Equation 4 belongs to an elliptic partial differential equation, and its exact solution cannot be obtained by analytical methods. The finite volume method has the characteristic of integral conservation having high efficiency when dealing with the lubrication calculation. It is most commonly used in the calculation of lubrication model with mass conservation. Therefore, the finite volume method is adopted to carry out the discrete analysis of Equation 4.

Firstly, isometric meshing is performed in the solution domain. There are $n$ nodes in the $x$ direction, and the grid points have coordinates $i$ in the $x$ direction. $p(i)$ is the fluid pressure at the grid point $i$. The basic idea of the finite volume method is to apply the conservation of mass to a particular control volume. Based on the integration of the pressure gradient and each control volume, Equation 4 can be discretely written as:

$$
\int_{x_{i-0.5}}^{x_{i+0.5}}\left[\frac{\partial}{\partial x}\left(\frac{p}{\mu} h^{3} \frac{\partial \rho}{\partial x}\right)\right] d x=\int_{x_{i-0.5}}^{x_{i+0.5}}\left\{12 u_{e} \frac{\partial[(1-\theta) \rho h]}{\partial x}\right\} d x
$$

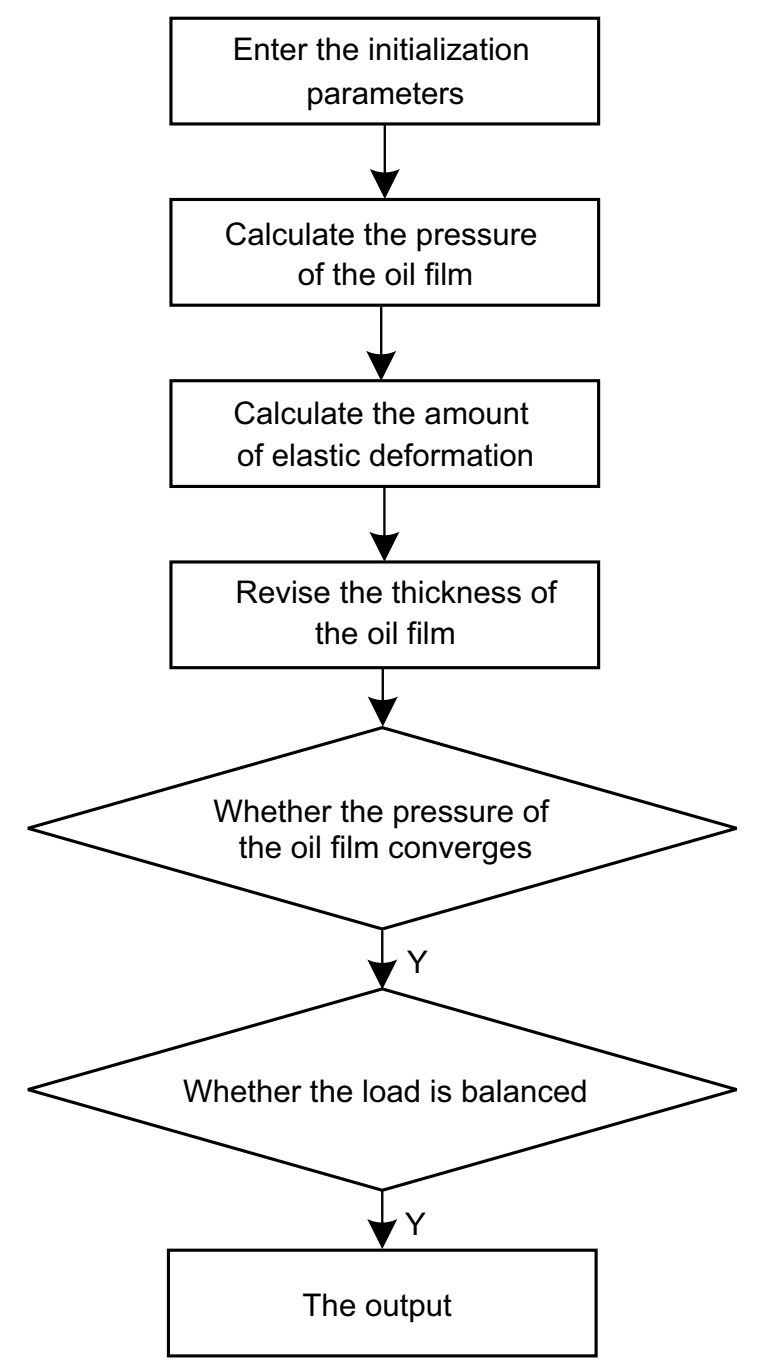

Figure 2. Flow chart of the simulation

Use the subscripts $P, E, W, e$ and $w$ to replace the subscripts $I, i+1, i-1, i+0.5$ and $i-0.5$, respectively, and use upwind schemes to discretise the right term of Equation 12, the equation after discretisation is:

$$
\left\{\begin{array}{l}
\frac{\rho_{e}}{\mu_{e}} h_{e}^{3} \frac{p_{E}-p_{P}}{\Delta x}-\frac{\rho_{W}}{\mu_{W}} h_{w}^{3} \frac{p_{P}-p_{W}}{\Delta x}=12 u_{e}\left[\left(1-\theta_{W}\right) \rho_{W} h_{w}-\left(1-\theta_{P}\right) \rho_{P} h_{P}\right] \\
h_{e}=0.5\left(h_{E}+h_{P}\right), \quad h_{w}=0.5\left(h_{W}+h_{P}\right) \\
\rho_{e}=0.5\left(\rho_{E}+\rho_{P}\right), \quad \rho_{w}=0.5\left(\rho_{W}+\rho_{P}\right) \\
\mu_{e}=0.5\left(\mu_{E}+\mu_{P}\right), \quad \mu_{w}=0.5\left(\mu_{W}+\mu_{P}\right)
\end{array}\right.
$$

By rearranging Equation 13, one can get:

$$
A_{W} P_{W}+A_{P} P_{P}+A_{E} P_{E}+B_{P} \theta_{P}+B_{W} \theta_{W}+C_{P}=0
$$

Equation 14 describes the linear relationship between $P$ and $\theta$. Therefore, the discretised lubrication model is a system of algebraic equations, which is expressed as:

$$
G(p, \theta)=A p+B \theta+c=0
$$

where $A$ is the matrix that collects information about $A_{P}, A_{W}$ and $A_{E}, B$ is the matrix that collects the $B_{W}$ and $B_{P}$ information, $c$ is the vector set that collects the 
boundary conditions and $C_{P}$ information. In order to improve the stability and convergence of the lubrication model, the FBN method is used to solve the lubrication model. By this method, the solution of the lubrication model is transformed from a constrained problem to an unconstrained problem, and the unconstrained problem can be solved quickly with the help of a commercial direct solver.

\section{Simulation conditions}

Define the slip ratio as $\zeta=\Delta u / u_{e}=1.0, \Delta u=u_{2}$ $-u_{1}$ [31]. The Hertz contact half-width of the ball is $b_{\mathrm{HZ}}$ and the calculated length in the $x$ direction in the simulation is $6 b_{\mathrm{HZ}} . X$ is the dimensional coordinate in the $x$ direction. $X=x / b_{H Z}$ the start coordinate of $X$ is -4 , and its end coordinate is 4 . The full ceramic ball bearing is a deep groove ball bearing, the silicon nitride ceramic material used in the bearing is obtained by hot isostatic pressing. The specific model is 6206CE, and the simulation parameters are shown in Table 2.

Table 2. The parameters of the $6206 \mathrm{CE}$ full ceramic ball bearing.

\begin{tabular}{lc}
\hline Parameters & Value \\
\hline The diameter of the inner raceway $(\mathrm{mm})$ & 36.98 \\
Diameter of the outer raceway $(\mathrm{mm})$ & 56.038 \\
Diameter of the ball $(\mathrm{mm})$ & 9.525 \\
The curvature radius of the inner raceway $(\mathrm{mm})$ & 4.91 \\
The curvature radius of the outer raceway $(\mathrm{mm})$ & 5.0 \\
The number of balls & 9 \\
Elastic modulus of the material of the bearing $(\mathrm{GPa})$ & 300 \\
Poisson's ratio of the bearing material & 0.27 \\
\hline
\end{tabular}

Simulation results and analysis

When the radial load $F=500 \mathrm{~N}$ and the rotational speed $n$ is $500 \mathrm{rpm}, 1000 \mathrm{rpm}$ and $2000 \mathrm{rpm}$ respectively, based on the above formula and simulation boundary condition conversion, the lubricant film thickness and pressure distribution in the contact area of full ceramic ball bearing are simulated and calculated respectively, as shown in Figure 3.

As can be seen from Figure 3, the lubricant film thickness in the contact area of the full ceramic ball bearing first decreases and then increases from the inlet to the outlet. In the middle of the lubrication area, the change in the lubricant film thickness slows down. The thickness of the lubricant film is the lowest near the position of $X=1$ in the exit area. Then the lubricant film begins to shrink, forming a necking-down effect. It is a typical characteristic of line contact steadystate elastohydrodynamic lubrication. Comparing the data in Figure 3, we can see that with an increase in the rotational speed, the thickness of the lubricant film increases correspondingly, and the change in the trend of the thickness of the lubricant film is more obvious. When the rotational speed becomes faster, the neckingdown effect at the outlet of the lubricant film would be more obvious. Moreover, the thickness of the lubricant film increases rapidly after the necking-down effect.

In addition, the pressure distribution of the lubricant film first increases and then decreases from the inlet to

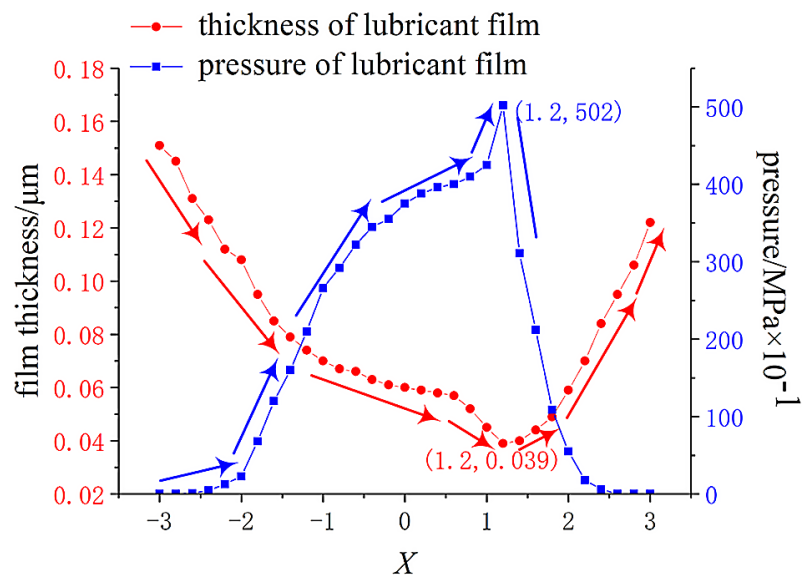

a) $n=500, F=500$

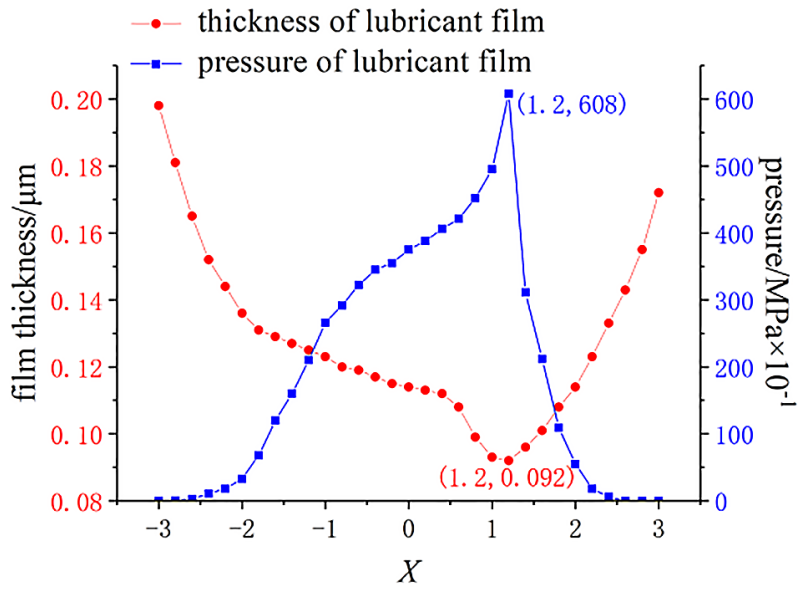

b) $n=1000, F=500$

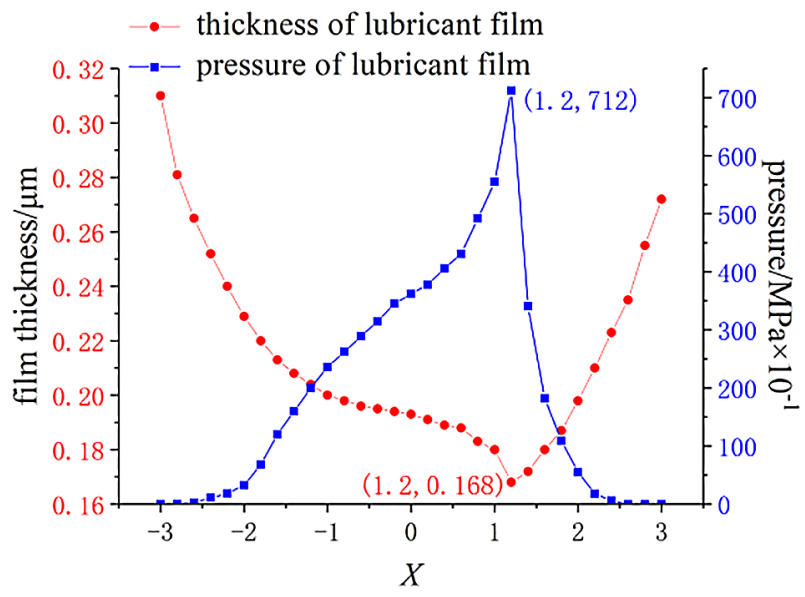

c) $n=2000, F=500$

Figure 3. The influence of the rotational speed on the distribution of the lubricant film. 
the outlet. In the middle of the lubrication zone, the lubricant film pressure distribution is similar to the Hertz contact pressure distribution. Near the position of $X=1$, the lubricant film pressure changes suddenly and reaches the maximum peak due to the necking-down effect. It is a typical characteristic of line contact steady-state elastohydrodynamic lubrication. By comparing the three pictures in Figure 3, it can be seen that with an increase in the rotational speed, the lubricant film pressure in the contact area increases, and the pressure change trend becomes more obvious. The necking-down effect has a greater impact on the oil pressure mutant peak.

When the rotational speed of bearing is $1000 \mathrm{rpm}$ and its radial load is $100 \mathrm{~N}$ and $1000 \mathrm{~N}$ respectively, the thickness and pressure distribution of lubricant film in the contact area of the full ceramic ball bearing are shown in Figure 4.

As can be seen from Figure 4, the influence of the load changes on the distribution of the lubricant film in the contact area of the full ceramic ball bearing is basically the same as that of rotational speed. By comparing Figure $3 b$ and Figure 4 , it can be seen that when the rotational

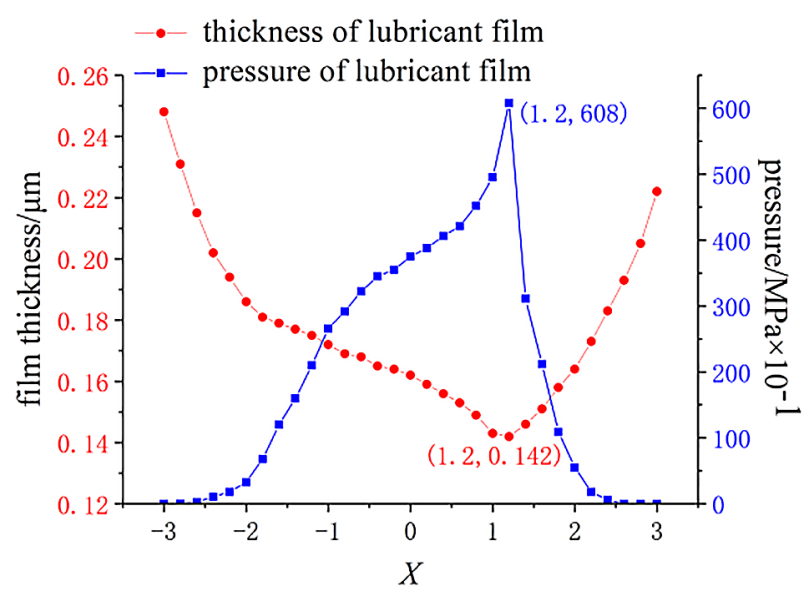

a) $n=1000, F=100$

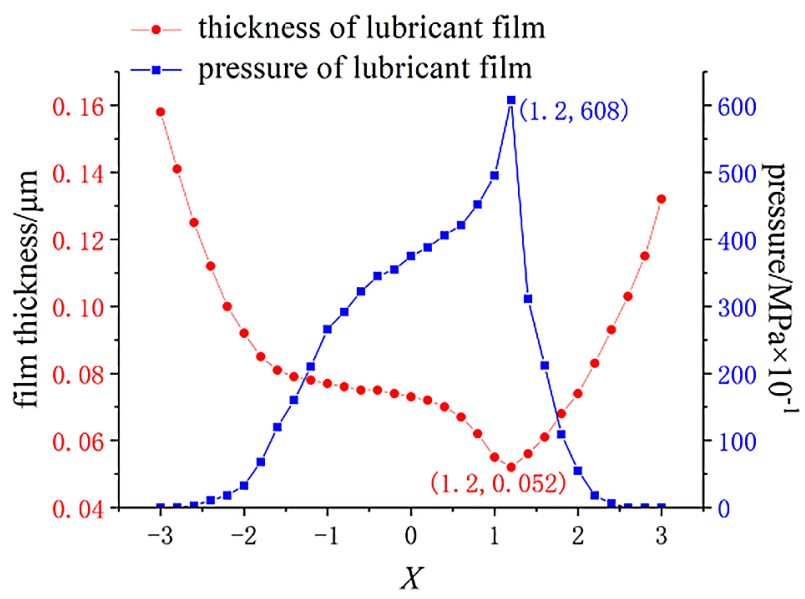

b) $n=1000, F=1000$

Figure 4. The influence of radial load on the distribution of the lubricant film. speed is constant, the thickness of the lubricant film decreases with an increase in the bearing load. Compared with the bearing rotational speed, the bearing load has a relatively small impact on the lubricant film thickness. Comparing the data, it can be concluded that the pressure distribution of the lubricant film in the bearing contact area is not affected by the load. Comparing the boundary conditions between the rotational speed and the load of the bearing, the rotational speed plays a leading role in the influence of the lubricant film distribution.

\section{EXPERIMENTAL RESEARCH}

Experimental theory and methods

The test was carried out on an SL-2000 ball-disc rolling lubricant film testing machine, and its test principle is shown in Figure 5. The optical glass plate and ceramic ball constitute the contact pair. Because the glass plate and ceramic ball are independently driven, by controlling the motor speed, the different rotational speed and sliding state at the contact point of full ceramic ball bearing can be simulated. The central shaft of the glass disk is loaded with an electric cylinder, which can simulate the different loads of the bearing. The lubricant distribution at the inlet of the contact area and the lubricant film interferogram in the contact area could be captured and stored by a charge-coupled device (CCD) after magnification by the microscope. In order to obtain the lubricant film thickness and shape, the interference image is processed offline using dual colour light modulation technology.

\section{Test conditions}

The glass plate used in the test is K9 glass with a diameter of $100 \mathrm{~mm}$. The contact plate is plated with a luminescent $\mathrm{Cr}$ film. The ceramic ball has G5 accuracy with a diameter of $9.525 \mathrm{~mm}$. The surface roughness of the glass disk and ceramic ball is about $0.06 \mu \mathrm{m}$ and $0.014 \mu \mathrm{m}$, respectively. The supply of lubricating oil is fixed and it is $30 \mu \mathrm{L}$. The line speed of the rolling ceramic ball is defined as $u_{1}$. The line speed of the raceway on the glass disc is defined as $u_{2}$ when it rotates. The rotational speed of the full ceramic ball bearing of $6206 \mathrm{CE}$ is defined as $n$. In order to keep consistent with the simulation conditions, the relationship between $u_{1}, u_{2}$ and $n$ is determined by calculation as shown in Table 3 .

Table 3. Relationship of the speeds of the 6206CE full ceramic ball bearing.

\begin{tabular}{cccc}
\hline No. & $n(\mathrm{rpm})$ & $u_{1}(\mathrm{~mm} / \mathrm{s})$ & $u_{2}(\mathrm{~mm} / \mathrm{s})$ \\
\hline 1 & 500 & 172 & 518 \\
2 & 1000 & 345 & 1036 \\
3 & 2000 & 691 & 2072 \\
\hline
\end{tabular}




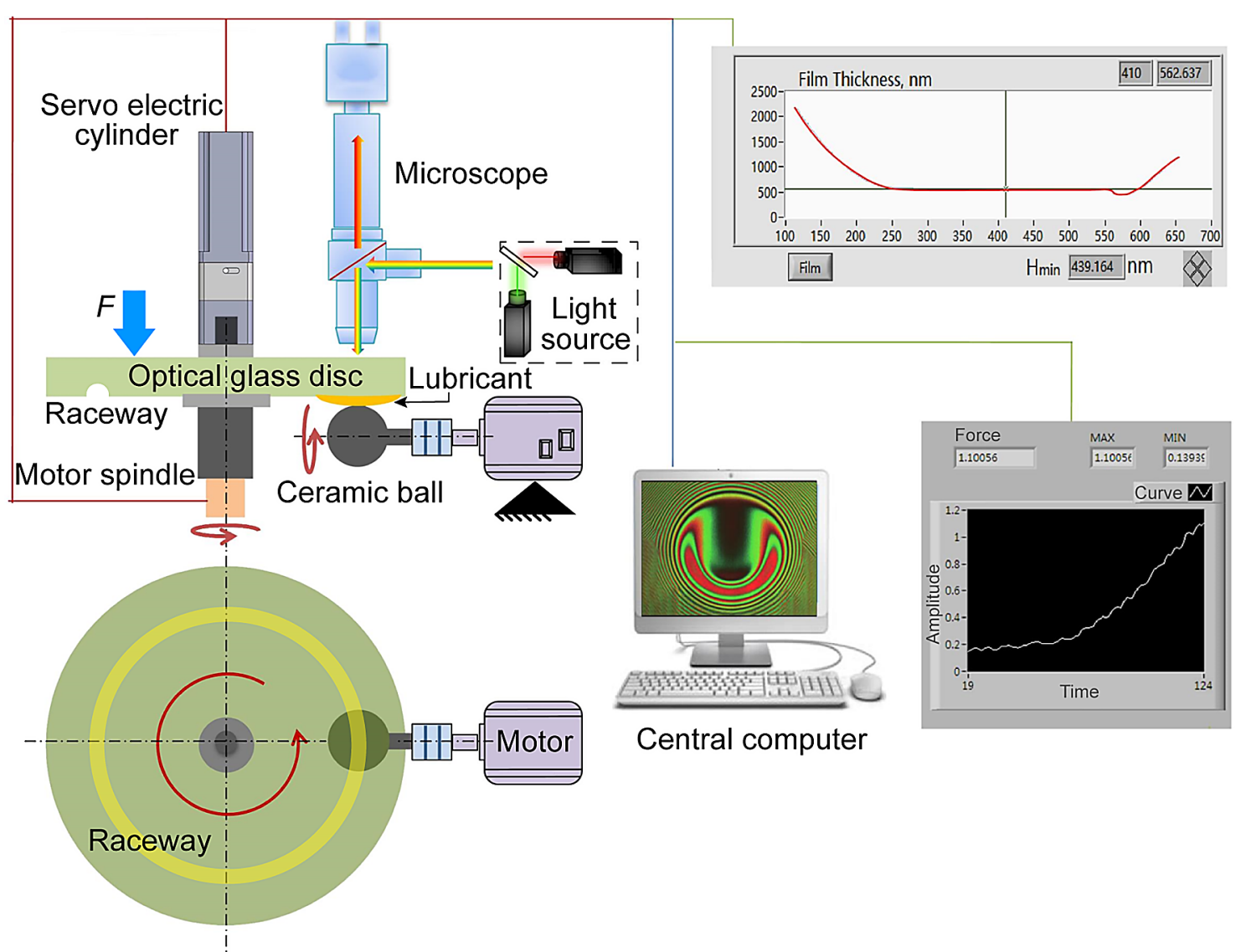

Figure 5. The test principle of the SL-2000 testing machine.

When the load of the glass disk is $F=500 \mathrm{~N}$ under the effect of an electric cylinder, the speeds are changed according to Table 3. The light interference images of the lubricant film under the same conditions with the simulation conditions are obtained are shown in Figure 6.

According to the results of the optical interference test of the lubricant film, the lubricant film formed at the contact between the ceramic ball and the turntable is the thinnest. At the same time, the lubricant film at the inlet of the ball and disc contact is thinner than the oil film at the outlet. Comparing the test results in Figure 6, it can be concluded that when the load is constant, with an increase in the speed, the thickness of the elastohydrodynamic lubricant film at the contact increases. At the same time, a lubricant film neckingdown effect is formed at the outlet. The greater the speed is, the more obvious the necking-down effect is at the outlet of the lubricant film. After the necking-down, the thickness of the lubricant film increases rapidly, which is consistent with the simulation results.

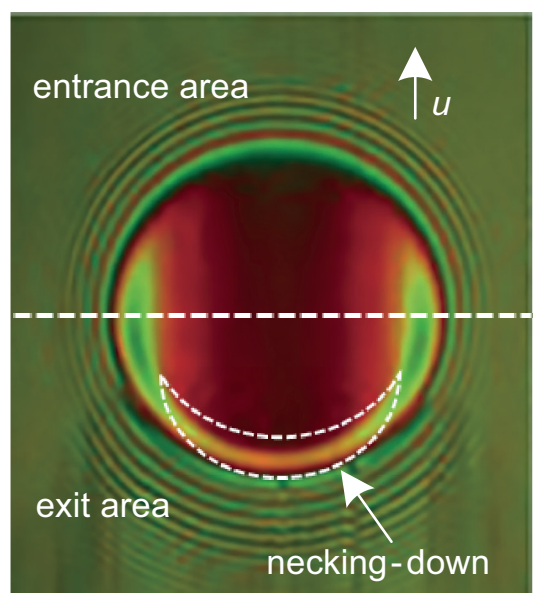

a) $u_{1}=172, u_{2}=518$

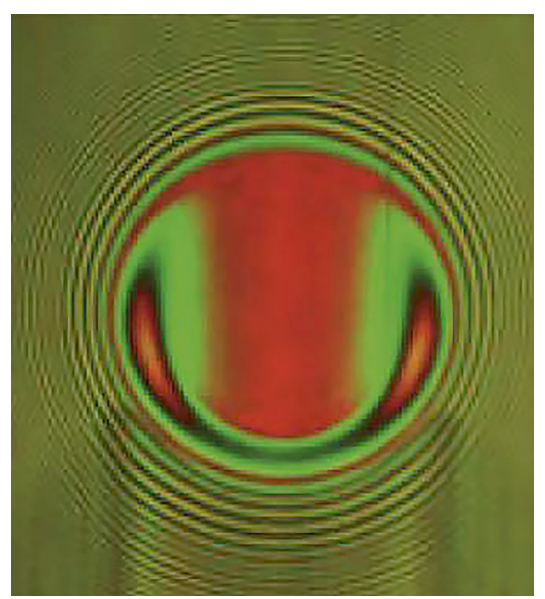

b) $u_{1}=345, u_{2}=1036$

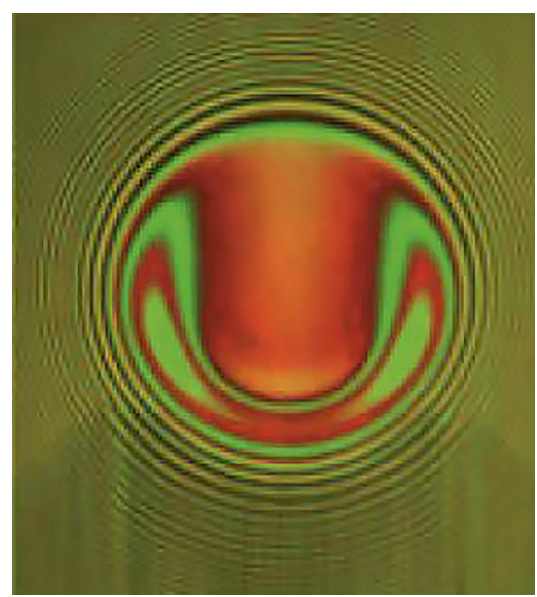

c) $u_{1}=691, u_{2}=2072$

Figure 6. Optical interference images of the lubricant film at different speeds. 


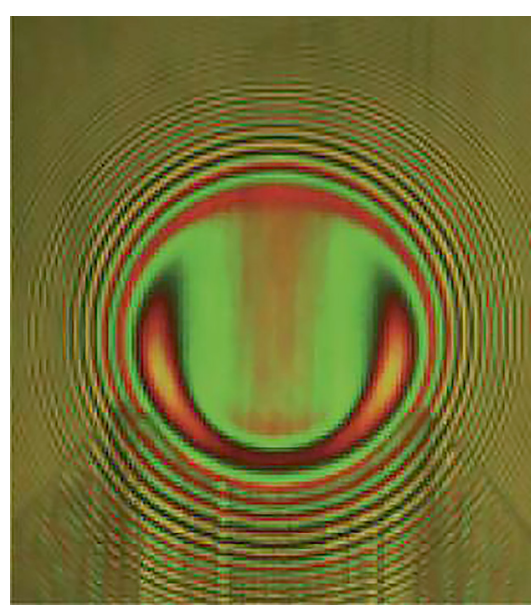

a) $F=100$

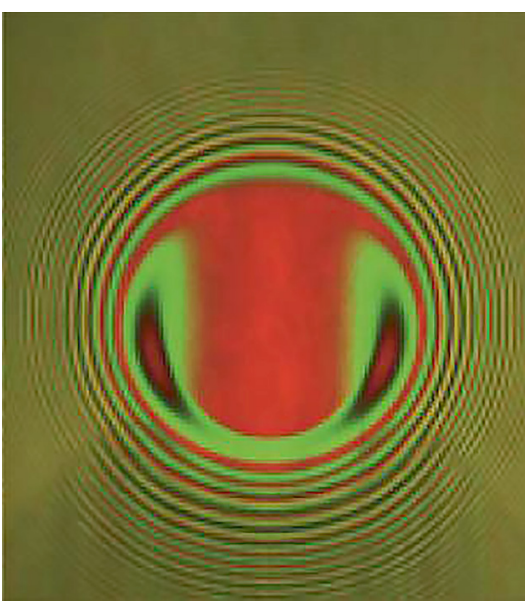

b) $F=500$

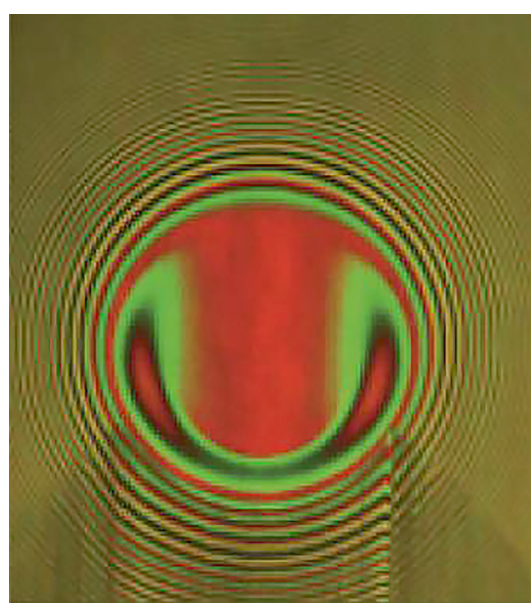

c) $F=1000$

Figure 7. Optical interference images of the lubricant film under different loads.

When the speeds are $u_{1}=345 \mathrm{~mm} / \mathrm{s}$ and $u_{2}=$ $=1036 \mathrm{~mm} / \mathrm{s}$, the load $F$ is changed to obtain the optical interference images of the lubricant film as shown in Figure 7.

Comparing the test results in Figure 7, it can be seen that when the speeds are constant, the lubricant film thickness becomes thinner as the load increases. However, compared with the speed, the change in the load has little effect on the lubricant film thickness. When the load changes, the distribution trend of lubricant film is almost unaffected. Due to the effect of the temperature rise in the test process, the viscosity of the lubricating oil decreases gradually in the contact area, so when the lubricant film is subjected to large shear, the surface sag is caused by the thermal viscosity wedge effect, which becomes obvious with an increase in the entrainment velocity. The appearance and size of the sag directly reflect the strength of the thermal effect. At the experimental entrainment velocity, the lubricant film is always in the state of fullfilm lubrication, showing the classic characteristics of elastohydrodynamic lubrication. In addition, influenced by the calculation of the corresponding relationship between the experimental temperature and the rotational speed, there is a measurement error in the recording of the film thickness data. In the process of collecting a large amount of data, it was found that the measurement error is about $3 \%$ by using data statistics.

When the load is constant and the rotational speed is changed, the distribution results of the lubricant film in the contact detected by the test are compared with the numerical simulation results as shown in Figure 8.

In Figure 8, the red curve is the numerical calculation results, and the blue curve is the experimental results under the same conditions. It can be concluded that the theoretical and experimental results of the lubricant film changes and distribution trend are in good agreement. The film thickness calculated by theoretical simulation is relatively large. According to data statistics, the thickness of the lubricant film formed at the contact coordinate $X$ of $0-1$, that is the contact origin and outlet area of ball and groove is thinner. The test results in this area are most close to the simulation calculation results.

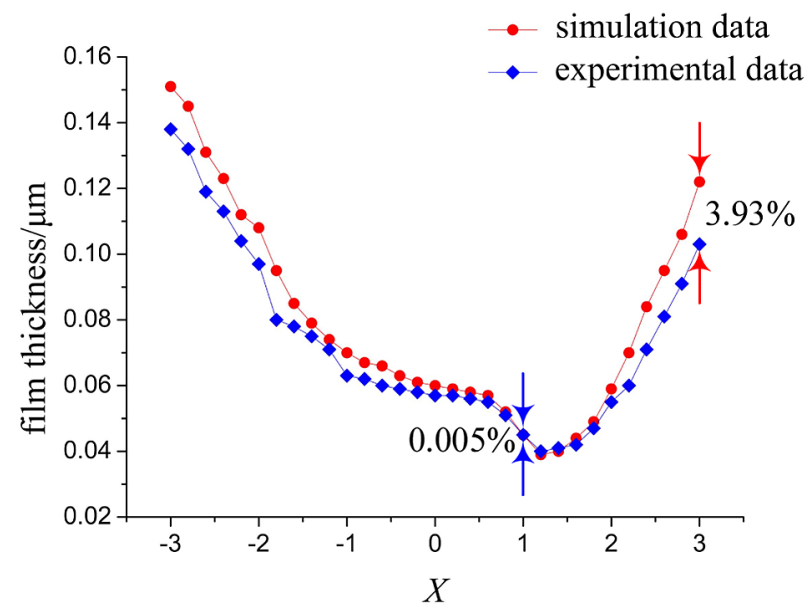

a) $n=500, F=500$

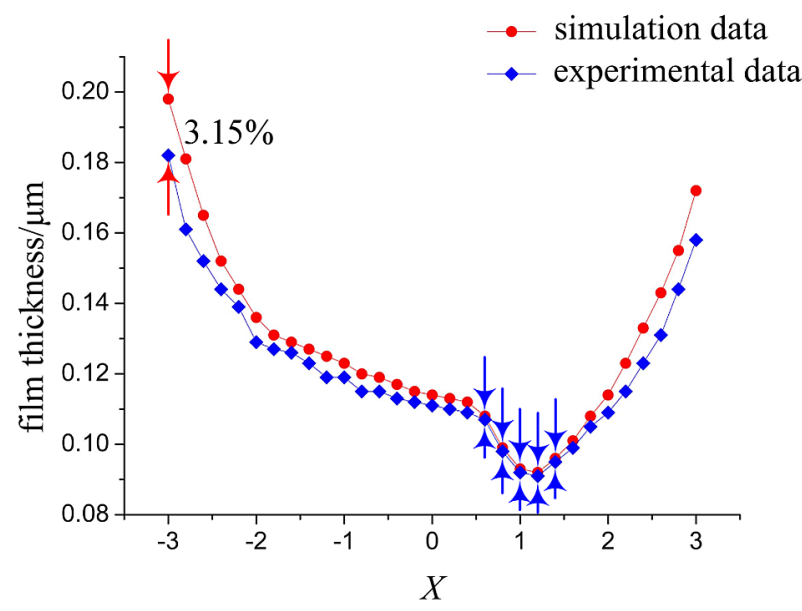

b) $n=1000, F=500$

Figure 8. Thickness distribution of the lubricant film at different rotational speeds. (Continue on next page) 


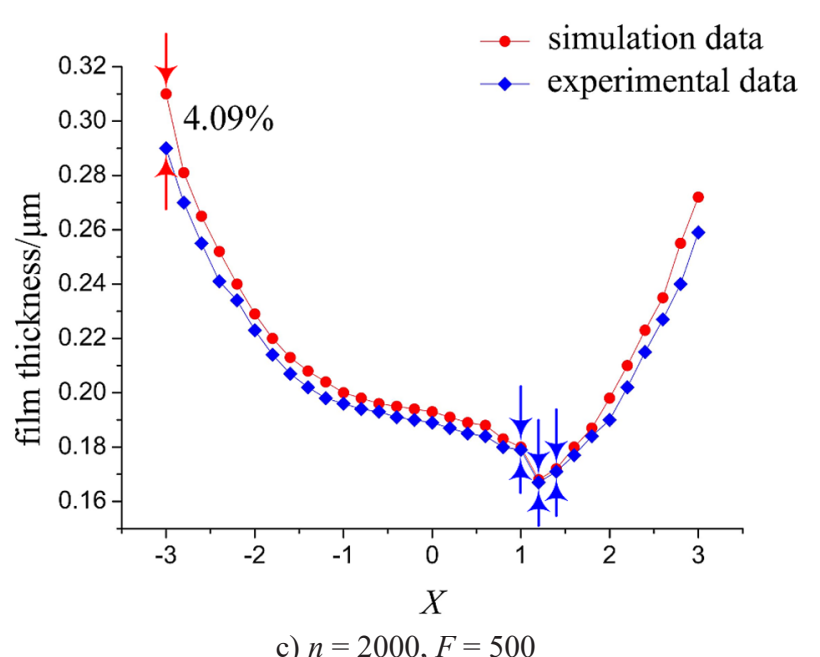

Figure 8. Thickness distribution of the lubricant film at different rotational speeds.

In other areas, the error between the simulation and test results becomes larger as the thickness of lubricant film increases. Based on the data statistics, when the load is $F=500 \mathrm{~N}$ and the rotational speed is $n=500 \mathrm{rpm}$, the maximum relative error between the theory and the test is $3.93 \%$. When the rotational speed is $n=1000 \mathrm{rpm}$, the maximum relative error between the theory and the test is $3.15 \%$. When the rotational speed is $n=2000 \mathrm{rpm}$, the maximum relative error between the theory and the test is $4.09 \%$. Although there are differences between the simulation and test results, as the rotational speed and entrainment velocity increase, the error rate between the theory and the test results becomes smaller. The above quantitative comparison shows the rationality of the distribution rules and the reliability of the experimental data.

When the rotational speed is constant and the load is changed, the results of the lubricant film distribution in the contact area detected by the test are compared with the numerical simulation results as shown in Figure 9.

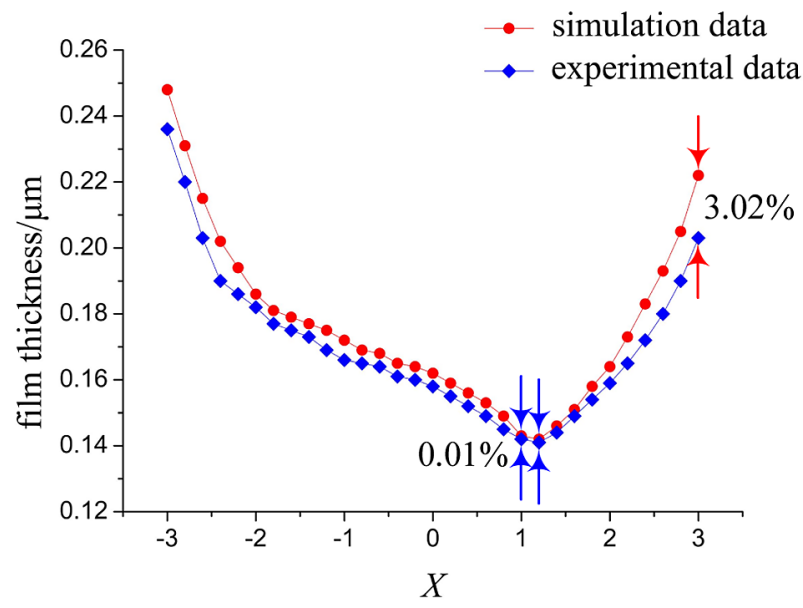

a) $n=1000, F=100$
The red curve in Figure 9 is the numerical calculation result, and the blue curve is the test result under the same conditions. It can be concluded that when the speed is constant and the load changes, the distribution of the lubricant film is basically consistent with the singlefactor change of the rotational speed. The difference between the simulation and the test results when the load changes is consistent with the rotational speed changes. Both the simulation and the test results could show the above law. Based on data statistics, when the rotational speed is $n=1000 \mathrm{rpm}$ and the value of load $F$ is $100 \mathrm{~N}$ and $1000 \mathrm{~N}$, the theoretical and experimental maximum relative errors are $3.02 \%$ and $4.75 \%$, respectively. This shows that as the load increases, the error rate between the theoretical and experimental results becomes larger, but they are all within the allowable error range. The above quantitative comparison also shows the rationality of the distribution rule and the reliability of the experimental data.

\section{DISCUSSION}

Using the established mathematical model, the lubricant film thickness and pressure distribution in the contact area of metal ball bearings and hybrid ceramic ball bearings are simulated. The simulation boundary conditions are selected as follows: rotational speed $n$ is $1000 \mathrm{rpm}$, radial load $F$ is $500 \mathrm{~N}$. The elastic modulus of bearing steel is $206 \mathrm{Gpa}$ and Poisson's ratio is 0.3. The simulation results are shown in Figure 10 and Figure 11.

It can be seen from Figure 10 that the overall change trend in the lubricant film thickness and pressure between ball bearings of different materials is relatively consistent. In the middle of the lubrication zone, the change in the lubricant film thickness of the metal ball bearing tends to be straight line, and the lowest oil film thickness occurs near $X>1$, forming a necking-down effect. By comparing ball bearings of different materials, it can

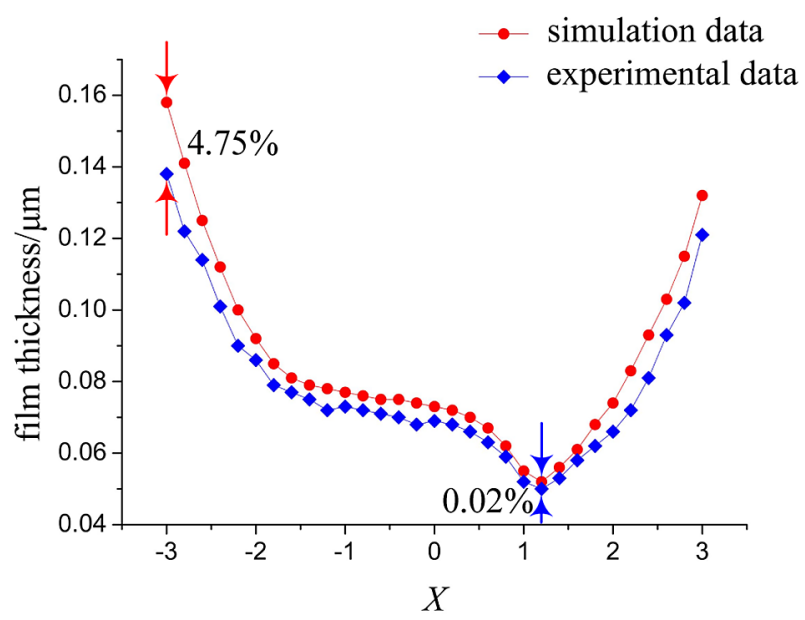

b) $n=1000, F=1000$

Figure 9. Thickness distribution of the lubricant film at different loads. 
be found that the lubricant film thickness in the contact area of the metal ball bearings is the largest, while that of the full ceramic ball bearings is the smallest. Because

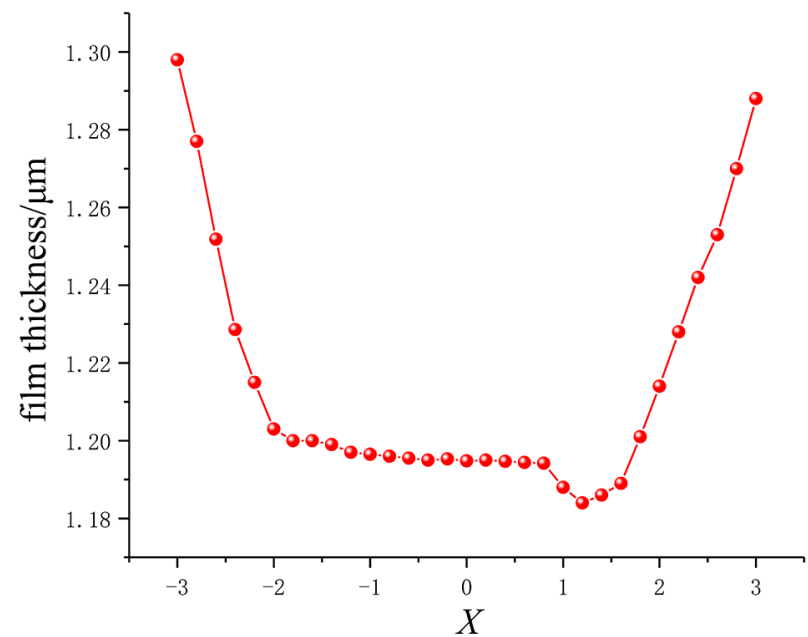

a) Metal ball bearing

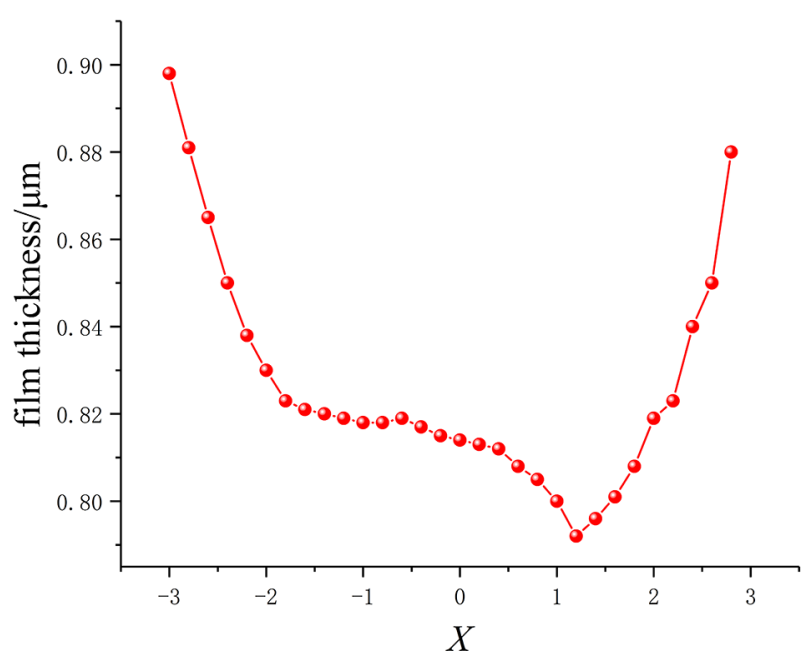

b) Hybrid ceramic ball bearing

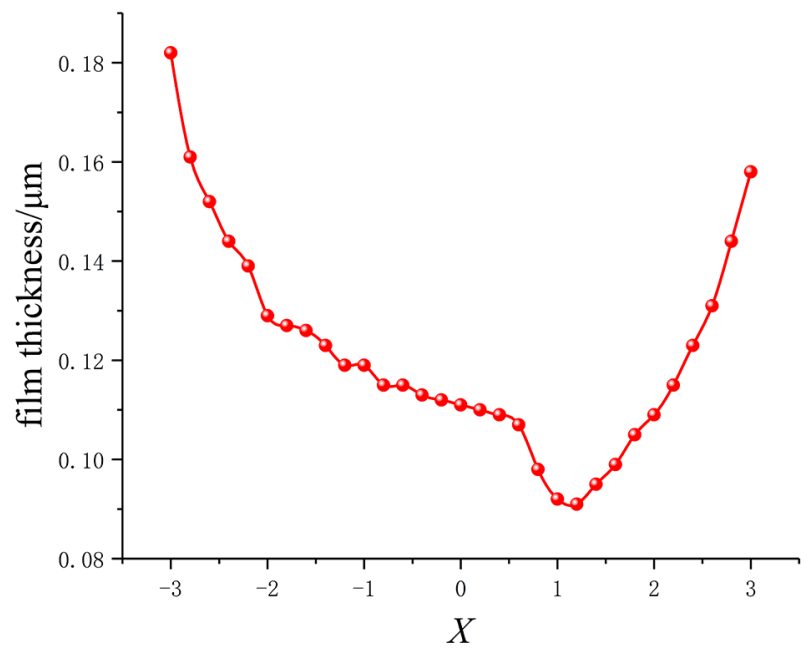

c) Full ceramic ball bearing

Figure 10. Thickness distribution of the lubrication film under different bearing materials. silicon nitride material has poor adhesion compared with bearing steel, when two bearings are in the same boundary condition, the metal material has a stronger adsorption

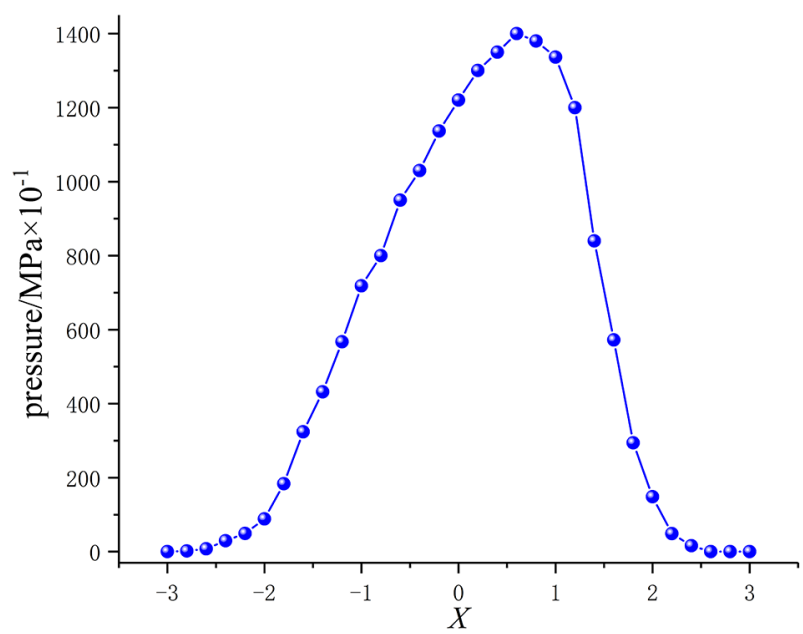

a) Metal ball bearing

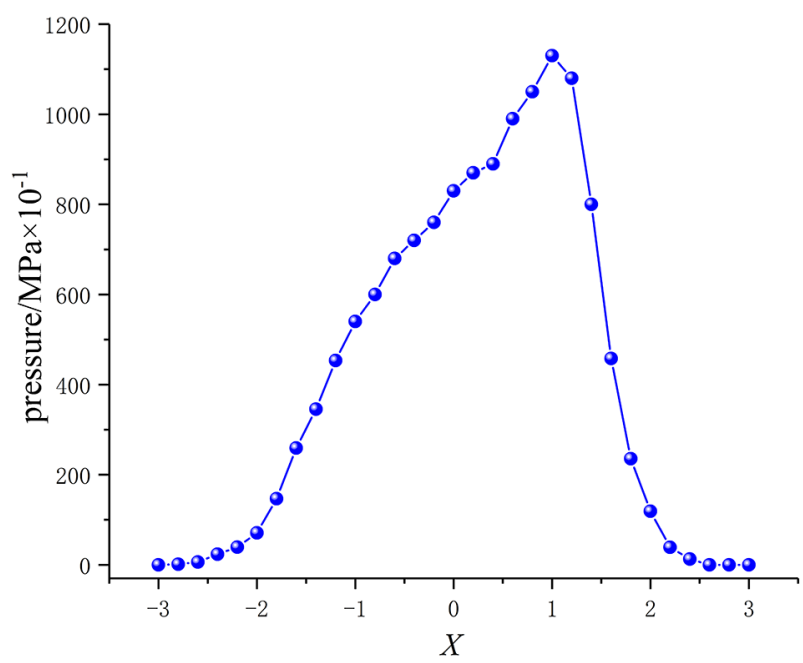

b) Hybrid ceramic ball bearing

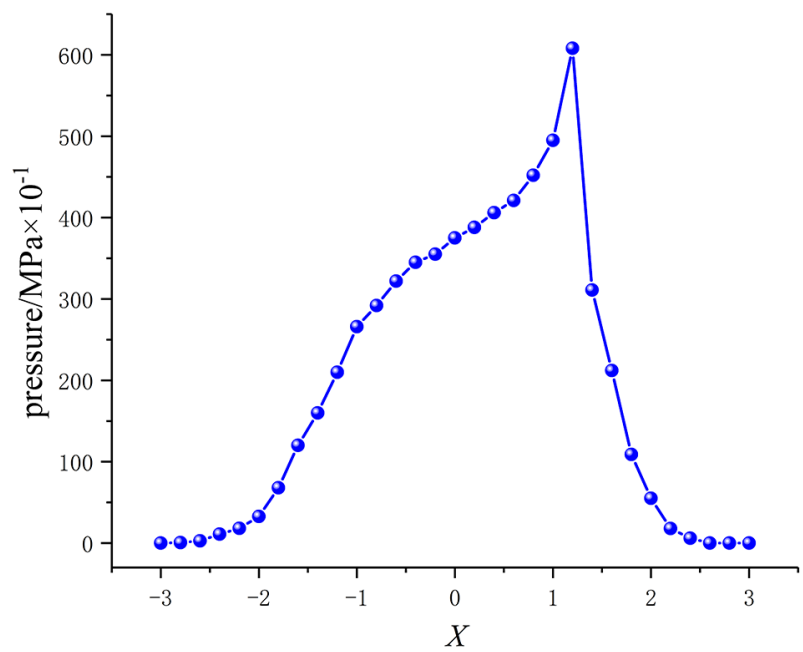

c) Full ceramic ball bearing

Figure 11. Pressure distribution of the lubricant film under different bearing materials. 
capacity for the lubricating oil, and the lubricant film thickness between the contact surfaces is larger. It can be from Figure 11 that the pressure distribution of the lubricant film first increases and then decreases from the inlet to the outlet. Among the different ball bearings, the change trend of the lubricant film pressure is relatively stable, and the phenomenon of the oil film pressure mutation caused by the necking-down effect is very different. Metal ball bearings have basically no pressure mutation phenomenon, but the lubricant film pressure in the contact area is relatively large.

\section{CONCLUSION}

- When the load is constant, the thickness of the lubricant film of the full ceramic ball bearing increases with an increase in its rotational speed. When the rotational speed is constant, the thickness of the lubricant film decreases with an increase in the load. Compared with the rotational speed of the bearing, its load has a relatively small impact on the thickness of the lubricant film.

- When the load is constant, the lubricant film pressure formed in the contact area of the full ceramic ball bearing increases with an increase in the rotation speed. When the rotational speed is constant, the pressure distribution of the lubricant film in the bearing contact area is not affected by the load. With an increase in the rotational speed, the necking-down effect has a greater influence on the pressure peak of the lubricant film. Only one pressure peak occurs in the oil film in the contact area of the full ceramic ball bearing.

- A distribution mathematical model of the lubricant film suitable for full ceramic ball bearings is established in this paper. The maximum relative error of the thickness of the lubricant film calculated by the mathematical model is $4.75 \%$ compared with the experimental results. It indicates that the model and its boundary conditions are credible. Compared with the calculation results of the model, it is clear that, between the rotational speed and the bearing load, the influence of the rotational speed changes on the distribution of the lubricant film plays a leading role.

\section{Acknowledgments}

The authors acknowledge the collective support granted by the National Natural Science Foundation of China (Grant No 52105196), the Department of Science and Technology of Liaoning Province (Grant No 2020BS-159), Young and Middle-aged Innovation Team of Shenyang (Grant No RC210343).

\section{REFERENCES}

1. Yan H.P., Wu Y.H., Li S.H., Zhang L.X., Zhang K. (2020): Research on sound field characteristics of full-ceramic angular contact ball bearing. Journal of the Brazilian Society of Mechanical Sciences and Engineering, 42(6), 1-16. doi: 10.1007/s40430-020-02295-5

2. Zhang K., Wang Z.N., Bai X.T., Shi H.T., Wang Q. (2020): Effect of preload on the dynamic characteristics of ceramic bearings based on a dynamic thermal coupling model. Advances in Mechanical Engineering, 12(1), 1-15. doi: 10. 1177/1687814020903851

3. Yan H.P., Wu Y.H., Sun J., Wang H., Zhang L.X. (2020): Acoustic model of ceramic angular contact ball bearing based on multi-sound source method. Nonlinear Dynamics, 99(2), 1155-1177. doi: 10.1007/s11071-019-05343-5

4. Shi J.H., Cao H.R., Chen X.F. (2019): Effect of angular misalignment on the static characteristics of rotating externally pressurized air journal bearing. Science China Technological Sciences, 62(9), 1520-1533. doi: 10.1007/ s11431-018-9429-4

5. Guo Y., Sun S.B., Wu X., Na J., Fung R.F. (2018): Experimental investigation on double-impulse phenomenon of hybrid ceramic ball bearing with outer race spall. Mechanical Systems and Signal Processing, (113), 189-198. doi: 10.1016/j.ymssp.2016.07.042

6. Nazir M. H., Khan Z. A., Saeed A. (2018): Experimental analysis and modelling of c-crack propagation in silicon nitride ball bearing element under rolling contact fatigue. Tribology International, (126), 386-401. doi: 10.1016/j. triboint.2018.04.030

7. Yao J.M., Wu Y.H., Sun J.; Tian J.X., Zhou P., Bao Z.G., Xia Z.X., Gao L.F. (2021): Friction and wear characteristics of silicon nitride ceramics under dry friction condition. Materials Research Express, 8(3),1-13.

8. Wang Y.L., Wang W.Z., Li Y.L., Zhao Z.Q. (2018): Lubrication and Thermal Failure Mechanism Analysis in HighSpeed Angular Contact Ball Bearing. Journal of Tribology, 140(3),1-10. doi: 10.1115/1.4038356

9. Zhang K., Wu X.C., Bai X.T., Wang Z.N., Zou D.F., Sun J. (2020): Effect of the Lubrication Parameters on the Ceramic Ball Bearing Vibration in Starved Conditions. Applied sciences, 10(4), 1237. doi: 10.3390/app10041237

10. Yang R., Jin Y.L., Hou L., Chen Y.S. (2018): Super-harmonic resonance characteristic of a rigid-rotor ball bearing system caused by a single local defect in outer raceway. Science China Technological Sciences, 61(8), 1184-1196. doi: 10.1007/s11431-017-9155-3

11. Zhou J.L., Wang X.P., Li X. (2020): Contact Analysis and Experimental Study of Full Ceramic Ball Bearing. Machinery Design \& Manufacture, (10), 11-14. doi: 10.19356/j. cnki.1001-3997.2020.10.003

12. Zhou J.L., Zhang W.W., Gu L.L. (2020): Optimal Design of Groove Curvature Radius Based on Full Ceramic Ball Bearing. Machinery Design \& Manufacture, (1), 26-28. doi: 10.19356/j.cnki.1001-3997.2020.01.007

13. Wen H.X., Sun J.J., Chen W. (2015): Review on Research Status Development Trend on Silicon Nitride Ceramic Bearings. Materials Reports, 29(17), 6-14.

14. Yuan J.L., Tong Y.L., Wang J.H., Lv B.H., Ma L.X., Wang D.F. (2021): Effect of lubricant viscosity on the performance and damage of high speed ball bearing. Journal of Harbin Institute of Technology, 53(1), 94-100. 
15. Su H., Dong X.B., Wei C.B., Lv C., Wu J.H. (2019): Application analysis of grease lubricated hybrid ball bearings in cold compressor. Cryogenics \& Superconductivity, 47(2), 1-7+32. doi: 10.16711/j.1001-7100.2019.02.001

16. Yan S., Lin B., Zhang X.F. (2018): State-of-the-art and key technologies of water lubricated ceramic spindle. Journal of Hebei University of Science and Technology, 39(6), 477-486.

17. Zhang T.G., Wang Y.Q., Xu C.H., Wang L.M. (2017): Analysis of the Thermal Elastohydrodynamic Lubrication of Water-lubricated Hybrid Ceramic Bearing. Journal of Mechanical Transmission, 41(10), 17-22. doi: 10.16578/j. issn.1004.2539.2017.10.004

18. Huang H., Liu X.L. (2012): Analysis of Thermal Elastohydrodynamic Lubrication for Ceramic Ball Bearing. $\mathrm{Lu}$ brication Engineering, 37(6), 46-51.

19. Han F., Wen H.X., Sun J.J., Wang W.; Fan Y.L., Jia J.H., Chen W. (2020): Tribological Properties of Si3N4-hBN Composite Ceramics Bearing on GCr15 under Seawater Lubrication. Materials, 13(3), 635. doi: 10.3390/ma 13030635

20. Galiev I. G., Hafizov K. A., Shaikhutdinov R. R., Galimov A. R. (2020): A Mathematical Model of individual Lubrication Systems for internal Combustion Engine Turbocharger Bearing Unit. Tekhnikai oborudovanie dlya sela, 4, 39-43.

21. Antonio-García A., Linares-Flores J., \& Arias-Montiel M. (2013): Numerical Investigations of the Lubrication Conditions in Hydrodynamic Bearings with Shaft Misalignment Effect. Ingeniería, investigación y tecnología, 14(1),89-98.

22. Cho I.S. (2015): The influence of boundary conditions on the lubrication characteristics of a journal bearing for reciprocating compressors. Journal of Mechanical Science and Technology, 29(2), 751-758. doi: 10.1007/s12206-0150135-9

23. Biswas N., Chakraborti P., Belkar S. (2016): An analytical and experimental approach for pressure distribution analysis of a particular lobe and plain bearing performance keeping in view of all impeding varying parameters associating with fixed lubrication SAE20W40. Journal of Mechanical Science and Technology, 30(5), 2187-2193. doi: 10.1007/ s12206-016-0426-9

24. Dmitrichenko N. F., Milanenko A. A., Hluhonets A. A., Minyaylo K. N. (2017): Method of Forecasting Durability of Bearings Rolling and Optimal Choice of Lubricants under Conditions of Flood Lubrication and Oil Starvation. Journal of Friction and Wear, 38(2), 126-131. doi: 10.3103/ S1068366617020076

25. Zhang D. (2019): Analysis on Tribology of Surface Texture in Rolling Bearing System. Bearing, (3), 30-34+57. doi: 10. 19533/j.issn1000-3762.2019.03.007

26. Ch V. K., Pandey R. K., Dinesh K. (2021): An exploration of frictional and vibrational behaviors of textured deep groove ball bearing in the vicinity of requisite minimum load. Friction, 9(6), 1749-1765. doi: 10.1007/s40544-0210495-3

27. Yao J.M., WuY.H., Sun J., Xu Y., Wang H., Zhou P. (2020): Research on the metamorphic layer of silicon nitride ceramic under high temperature based on molecular dynamics. The International Journal of Advanced Manufacturing Technology, 109(5-6), 1249-1260. doi: 10.1007/s00170-02005685-0

28. Liu J., Shao Y.M. (2018): An improved analytical model for a lubricated roller bearing including a localized defect with different edge shapes. Journal of Vibration and Control, 24(17), 3894-3907. doi: 10.1177/1077546317716315

29. Bi Z.M., Mueller D. W., Zhang C. W. (2021): State of the art of friction modelling at interfaces subjected to elastohydrodynamic lubrication (EHL). Friction, 9(2), 207-227. doi: 10.1007/s40544-020-0449-1

30. Gong J.Y., Jin Y., Liu Z.L., Jiang H., Xiao M.H. (2019): Study on influencing factors of lubrication performance of waterlubricated micro-groove bearing. Tribology International, 129, 390-397. doi: 10.1016/j.triboint.2018.08.035

31. Li X.M., Guo F., Poll G., Fei Y., Yang P. (2021): Grease film evolution in rolling elastohydrodynamic lubrication contacts. Friction, 9, 179-190. doi: 10.1007/s40544-0200381-4 